\title{
Usage Research of Class Teaching Skills Based on Time Characters
}

\author{
Qi Yan ${ }^{1, a}$ \\ ${ }^{1}$ SHAOGUAN University YINGDONG Agriculture \\ Science and Engineering college, \\ SHAOGUAN City, GUANGDONG Province, China \\ a460517355@qq.com,
}

\begin{abstract}
Teaching skills were analyzed by SPSS based on microteaching videos. The results showed that there was no significant difference between 5 mins division, $15 \mathrm{mins}$ division and skills usage, while significant difference between the 10mins division, 20mins division and skill usage. The sorting of division effect was: 20mins division $>10$ mins division $>5$ mins division $>15$ mins division. Language and explanation were not affected by time. In 10mins division, only did class management have significant differences between time and skills. In 20mins division, there was significant difference in skills of questioning, changing, strengthening and class management. It was effective to arrange training time rationally for improving teaching efficiency.
\end{abstract}

Keywords: class teaching skills, time characters, minute division, difference

\section{Introduction}

It is common cognition for teaching to enter into practice stage from theory stage in modern teaching development. American teachers' qualification examination system is changing, from static examination to concrete practice ${ }^{[1]}$. Microteaching is a method of training Normal School Students' teaching capability by using limited time, space and scene practice, where class teaching capabilities were decomposed into 10 single skills including introduction, language, blackboard writing, body language, demonstration, feedback in strengthening, explanation, questioning, ending and management, etc, which made trainers to exercise teaching skills under controllable situation $^{[2]}$. There was close inner association between time and teaching. From the beginning of the scientific exploration research in teaching time (J.B.Carroll), ${ }^{[3]}$ lots of theories and practice researches were developed, and those of teaching time were focused on relationship among teaching effect and time, time management ${ }^{[4]}$, using strategy and rational classification ${ }^{[5]}$, etc. However,

\author{
Jun $\mathbf{L i}^{1, b, *}$ \\ ${ }^{1}$ SHAOGUAN University YINGDONG Agriculture \\ Science and Engineering college, \\ SHAOGUAN City, GUANGDONG Province, China \\ b466874794@qq.com \\ *Corresponding author
}

quantitative researches about relationship between teaching skills and time were still less.

In view of the mentioned above, combined with different analysis methods, this research began from time characters of teaching skills usage. Skills usage and manifestations of difference in ten skills in each minute division were quantitative analyzed to display the expression of skills usage in aspect of time characters and to provide scientific basis for class training more effective and rational.

\section{Research Object and Method}

\subsection{Research Object}

The 11 grade students of horticulture major in SHAOGUAN University were observed from April to June in 2014 year. During their 4 times microteaching training, 127 valid videos were collected on April 21, April 28, May 5 and May 29.

\subsection{Research Method}

According to literature monographs related with teaching skills and practice, 10 teaching skills were analyzed quantitatively in this paper, that is, introduction, language, questioning, explanation, changing, strengthening, demonstration, blackboard writing, ending and class management. Through repeatedly observation, statistical method was used to distinguish every skill by taking signal 1 and 0 which represented usage and non-usage respectively (table 1). All videos were divided into 4 kinds of $5 \mathrm{mins}$ division, $10 \mathrm{mins}$ division, $15 \mathrm{mins}$ division, 20mins division.

Through using EXCEL to induct and summary original data, the data were analyzed by SPSS. 
Table 1 class teaching skills service condition

\begin{tabular}{|c|c|c|c|c|c|}
\hline \multicolumn{2}{|c|}{ time division } & first & second & third & fourth \\
\hline \multicolumn{2}{|c|}{ video numbers } & 34 & 29 & 31 & 33 \\
\hline \multirow{4}{*}{\begin{tabular}{c} 
Times \\
of \\
skills \\
\cline { 2 - 6 }
\end{tabular}} & introduction & 25 & 19 & 19 & 20 \\
\cline { 2 - 6 } & language & 34 & 29 & 31 & 33 \\
\cline { 2 - 6 } & questioning & 32 & 25 & 26 & 29 \\
\cline { 2 - 6 } & explanation & 34 & 29 & 31 & 33 \\
\cline { 2 - 6 } & changing & 31 & 28 & 31 & 33 \\
\cline { 2 - 6 } & $\begin{array}{c}\text { strengthening } \\
\text { usagenstratio } \\
\text { n }\end{array}$ & 32 & 26 & 28 & 32 \\
\cline { 2 - 6 } & $\begin{array}{c}\text { blackboard } \\
\text { writing }\end{array}$ & 33 & 29 & 30 & 33 \\
\cline { 2 - 6 } & ending & 12 & 5 & 5 & 11 \\
\cline { 2 - 6 } & $\begin{array}{c}\text { class } \\
\text { management }\end{array}$ & 29 & 23 & 28 & 28 \\
\hline
\end{tabular}

\section{Results and Analysis}

\subsection{Skills Usage Analysis in Different Division}

\section{1) Distribution of Skill Usage Time}

According to table 2, the main usage period was in 5 to 56 minutes, among which 1 to 5 minutes and 36+ minutes were the least, no more than $5 \%$, segment between 11 to 15 minutes was the most, about $30 \%$, the following segment sequence was 6 to 10 minutes, 16 to 20 minutes, 21-25 minutes, about 24\%, $18 \%, 14 \%$ successively. Therefore, teaching skill usage time was focus on the segment of 6 to 25 minutes.

Table 2 time distribution of class teaching skill usage

\begin{tabular}{|c|c|c|}
\hline $\begin{array}{c}\text { segment } \\
\text { /min }\end{array}$ & $\begin{array}{c}\text { Video } \\
\text { numbers }\end{array}$ & $\begin{array}{c}\text { percentage } \\
/ \%\end{array}$ \\
\hline $1-5$ & 2 & 1.58 \\
\hline $6-10$ & 23 & 18.11 \\
\hline $11-15$ & 37 & 29.13 \\
\hline $16-20$ & 31 & 24.41 \\
\hline $21-25$ & 18 & 14.17 \\
\hline $26-30$ & 7 & 5.51 \\
\hline $31-35$ & 5 & 3.94 \\
\hline $36-$ & 4 & 3.15 \\
\hline
\end{tabular}

\section{2) Difference Analysis of Skills in Each Segment of} Various Divisions

According to table 3, there was rising trend with speech time increasing in the aspect of usage skills comprehensiveness. The segment between 26 to 30 minutes was the highest point, after which the comprehensiveness decreased gradually. There were significant differences in each segment of $10 \mathrm{mins}$ division and $20 \mathrm{mins}$ one, nonsignificant difference in that of $5 \mathrm{mins}$ and $15 \mathrm{mins}$ divisions. By inter-comparison the above 4 type divisions, the difference of the 20mins division was more significant and clearer, and least significant and non-rationality in the 15 mins division. Therefore, in 20munute division there was the best, clearest and most rational teaching effect.

In 5 mins division, besides segment of 6-10 minutes, there was significant difference between 1-5 minutes segment and the other ones. However, the sample number of 1-5 minutes segment was less, and the manifestations of difference was unstable, thus, there was still to be verified in future about its differences.

In 10mins division, there were significant differences between segment of 1-10 minutes and 21-30 minutes, 36+ minutes. The segment of 11-20 minutes was transitional part with the common characters as in short time and long time segment, so that there were no significant differences between the segment of 11-20 minutes and the other ones.

In 15mins division, there was no significant difference among the three segments. The main reason was that there were common characters among the three segments, which resulted in difference disappearing in the two segments once the above two divisions mixed.

In 20mins division, there were significant differences in the two segments in which the common characters existing in 10 minute division were fused and the differences were amplified further. Thus, this division had the best segment effect.

Table 3 usage changes of skills in different minute divisions

\begin{tabular}{|c|c|c|c|}
\hline $\begin{array}{c}\text { minute } \\
\text { division }\end{array}$ & $\begin{array}{c}\text { segmentation } \\
/ \mathrm{min}\end{array}$ & $\begin{array}{c}\text { Video } \\
\text { numbers }\end{array}$ & $\bar{x} \pm s$ \\
\hline \multirow{8}{*}{$5 \mathrm{mins}$} & $1-5$ & 2 & $6.50 \pm 2.12^{\mathrm{a}}$ \\
\hline & $6-10$ & 23 & $7.84 \pm 1.39^{\mathrm{ab}}$ \\
\hline & $11-15$ & 37 & $8.27 \pm 1.19^{b}$ \\
\hline & $16-20$ & 31 & $8.35 \pm 1.38^{b}$ \\
\hline & $21-25$ & 18 & $8.67 \pm 1.08^{\mathrm{b}}$ \\
\hline & $26-30$ & 7 & $9.14 \pm 0.69^{\mathrm{b}}$ \\
\hline & $31-35$ & 5 & $8.80 \pm 0.84^{b}$ \\
\hline & $36-$ & 4 & $8.75 \pm 0.96^{b}$ \\
\hline \multirow{4}{*}{$10 \mathrm{mins}$} & $1-10$ & 25 & $7.76 \pm 1.45^{\mathrm{a}}$ \\
\hline & $11-20$ & 68 & $8.31 \pm 1.27^{\mathrm{ab}}$ \\
\hline & $21-30$ & 25 & $8.80 \pm 1.00^{b}$ \\
\hline & $31-$ & 9 & $8.78 \pm 0.83^{b}$ \\
\hline \multirow{3}{*}{$15 \mathrm{mins}$} & $1-15$ & 62 & $8.06 \pm 1.32^{\mathrm{a}}$ \\
\hline & $16-30$ & 56 & $8.55 \pm 1.23^{\mathrm{a}}$ \\
\hline & $31-$ & 9 & $8.78 \pm 0.83^{\mathrm{a}}$ \\
\hline \multirow{2}{*}{$20 \mathrm{mins}$} & $1-20$ & 93 & $8.16 \pm 1.34^{\mathrm{a}}$ \\
\hline & $21-$ & 34 & $8.79 \pm 0.95^{\mathrm{b}}$ \\
\hline
\end{tabular}

Ps: in the same division, different lowercase letters represent significant differences in the level of 0.05

\subsection{Difference Analysis of single skill in different divisions}

According to table 3 , in the 4 minute divisions, it was in 10 mins division and 20mins division that showed the rational significance. Therefore, differences of single skills in $10 \mathrm{mins}$ and $20 \mathrm{mins}$ division were analyzed in this research.

On the basis of table 4 and 5, language and explanation was the basic skills, no relationship with teaching time.

1) Changes in Different Segments of Single Skill usage in 10mins Division

In the 10mins division, among the ten teaching skills, it was the skills of demonstration, blackboard writing and ending that had upper and lower small amplitude fluctuation with teaching time increasing, not significant. Meanwhile, the skills of introduction, questioning, changing, strengthening and class management presented increasing trend with the increasing time. Introduction skill had small increasing trend from $31^{\text {st }}$ minute with no significance while before $30^{\text {th }}$ minute this skill had no changes. Questioning skill had minimal increase amplitude with time prolonging but no significance. Changing skill kept stagnant after $11^{\text {th }}$ minutes 
before which this skill was increasing slowly but no significance. Strengthening skill usage kept slowly increase during the period of 1-20 minutes and stayed stable after that, but no significance for small increase amplitude. Class management skill had obvious changes during the observation. From $1^{\text {st }}$ to $20^{\text {th }}$ minutes this skill usage was slowly increasing, after $21^{\text {st }}$ minutes, the increase amplitude had fast growth and kept invariant consequently. There was significant difference compared $20^{\text {th }}$ minutes before with $20^{\text {th }}$ minutes after due to great increase amplitude. (table 4\&5)(Skill number 1 represents the introduction skill. Skill number 2 represents the language skill. Skill number3 represents the questioning skill. Skill number 4 represents explanation skill. Skill number 5 represents the changing skill. Skill number 6 represents the strengthening skill. Skill number 7 represents the demonstration skill. Skill number 8 represents the blackboard writing skill. Skill number 9 represents the ending skill. Skill number 10 represents the class management skill.)

Table 4 each skill usage change in 10 minute division

\begin{tabular}{|c|c|c|c|c|}
\hline $\begin{array}{l}\text { segment } \\
\text { /min }\end{array}$ & $\begin{array}{c}\text { skills } \\
\text { numbers }\end{array}$ & $\bar{x} \pm s$ & $\begin{array}{c}\text { skills } \\
\text { numbers }\end{array}$ & $\bar{x} \pm s$ \\
\hline $1-10$ & \multirow{4}{*}{1} & $0.64 \pm 0.49^{\mathrm{a}}$ & \multirow{4}{*}{6} & $0.88 \pm 0.33^{\mathrm{a}}$ \\
\hline $11-20$ & & $0.63 \pm 0.49^{\mathrm{a}}$ & & $0.91 \pm 0.29^{\mathrm{a}}$ \\
\hline $21-30$ & & $0.64 \pm 0.49^{\mathrm{a}}$ & & $1.00 \pm 0.00^{\mathrm{a}}$ \\
\hline $31-$ & & $0.89 \pm 0.33^{\mathrm{a}}$ & & $1.00 \pm 0.00^{\mathrm{a}}$ \\
\hline $1-10$ & \multirow{4}{*}{2} & $1.00 \pm 0.00^{\mathrm{a}}$ & \multirow{4}{*}{7} & $0.76 \pm 0.44^{\mathrm{a}}$ \\
\hline $11-20$ & & $1.00 \pm 0.00^{\mathrm{a}}$ & & $0.84 \pm 0.37^{\mathrm{a}}$ \\
\hline $21-30$ & & $1.00 \pm 0.00^{\mathrm{a}}$ & & $0.84 \pm 0.37^{\mathrm{a}}$ \\
\hline $31-$ & & $1.00 \pm 0.00^{\mathrm{a}}$ & & $0.56 \pm 0.53^{\mathrm{a}}$ \\
\hline $1-10$ & \multirow{4}{*}{3} & $0.80 \pm 0.41^{\mathrm{a}}$ & \multirow{4}{*}{8} & $1.00 \pm 0.00^{\mathrm{a}}$ \\
\hline $11-20$ & & $0.87 \pm 0.34^{\mathrm{a}}$ & & $0.97 \pm 0.17^{\mathrm{a}}$ \\
\hline $21-30$ & & $0.96 \pm 0.20^{\mathrm{a}}$ & & $1.00 \pm 0.00^{\mathrm{a}}$ \\
\hline $31-$ & & $1.00 \pm 0.00^{\mathrm{a}}$ & & $1.00 \pm 0.00^{\mathrm{a}}$ \\
\hline $1-10$ & \multirow{4}{*}{4} & $1.00 \pm 0.00^{\mathrm{a}}$ & \multirow{4}{*}{9} & $0.12 \pm 0.33^{\mathrm{a}}$ \\
\hline $11-20$ & & $1.00 \pm 0.00^{\mathrm{a}}$ & & $0.26 \pm 0.44^{\mathrm{a}}$ \\
\hline $21-30$ & & $1.00 \pm 0.00^{\mathrm{a}}$ & & $0.36 \pm 0.49^{\mathrm{a}}$ \\
\hline $31-$ & & $1.00 \pm 0.00^{\mathrm{a}}$ & & $0.33 \pm 0.50^{\mathrm{a}}$ \\
\hline $1-10$ & \multirow{4}{*}{5} & $0.84 \pm 0.37^{\mathrm{a}}$ & \multirow{4}{*}{10} & $0.72 \pm 0.46^{\mathrm{ab}}$ \\
\hline $11-20$ & & $1.00 \pm 0.00^{\mathrm{a}}$ & & $0.82 \pm 0.38^{\mathrm{b}}$ \\
\hline $21-30$ & & $1.00 \pm 0.00^{\mathrm{a}}$ & & $1.00 \pm 0.00^{c}$ \\
\hline $31-$ & & $1.00 \pm 0.00^{\mathrm{a}}$ & & $1.00 \pm 0.00^{\mathrm{c}}$ \\
\hline
\end{tabular}

Ps: In the same team, different lowercase letters represent significant difference in the level of 0.05 , and different capital letters represent great significant difference in the level of 0.01 .

2) Change in Different Segments of Single Skill Usage in 20mins Division

According to table 5, only demonstration skill was there negative relationship with increasing teaching time, that is, longer time, less skill usage, while the other 7 skills, including introduction, questioning, changing, strengthening, blackboard writing, ending and class management, showed increasing trend due to increase of the teaching time. The 4 skills usage of demonstration, introduction, blackboard writing and ending had changes to some extent with minimal increase amplitude so that there was no significant difference. The 4 skills usage of questioning, changing, strengthening and class management showed large increase amplitude in 20 minutes before and after with significant differences, among which strengthening and class management displayed great significant differences for the largest increase amplitude.

Table 5 each skill usage change in 20 minute division

\begin{tabular}{|c|c|c|c|c|}
\hline$\underset{\text { Segment }}{\text { Sin }}$ & $\begin{array}{c}\text { skill } \\
\text { numbers }\end{array}$ & $\bar{x} \pm s$ & $\begin{array}{c}\text { skill } \\
\text { numbe } \\
\text { rs }\end{array}$ & $\bar{x} \pm s$ \\
\hline $1-20$ & \multirow{2}{*}{1} & $0.63 \pm 0.48^{\mathrm{a}}$ & \multirow{2}{*}{6} & $0.90 \pm 0.30^{\mathrm{a} A}$ \\
\hline $20-$ & & $0.71 \pm 0.46^{\mathrm{a}}$ & & $1.00 \pm 0.00^{\mathrm{bB}}$ \\
\hline $1-20$ & \multirow{2}{*}{2} & $1.00 \pm 0.00^{\mathrm{a}}$ & \multirow{2}{*}{7} & $0.82 \pm 0.39^{\mathrm{a}}$ \\
\hline $20-$ & & $1.00 \pm 0.00^{\mathrm{a}}$ & & $0.76 \pm 0.43^{\mathrm{a}}$ \\
\hline $1-20$ & \multirow{2}{*}{3} & $0.85 \pm 0.36^{\mathrm{a}}$ & \multirow{2}{*}{8} & $0.98 \pm 0.15^{\mathrm{a}}$ \\
\hline $20-$ & & $0.97 \pm 0.17^{b}$ & & $1.00 \pm 0.00^{\mathrm{a}}$ \\
\hline $1-20$ & \multirow{2}{*}{4} & $1.00 \pm 0.00^{\mathrm{a}}$ & \multirow{2}{*}{9} & $0.23 \pm 0.42^{\mathrm{a}}$ \\
\hline $20-$ & & $1.00 \pm 0.00^{\mathrm{a}}$ & & $0.35 \pm 0.49^{\mathrm{a}}$ \\
\hline $1-20$ & \multirow{2}{*}{5} & $0.96 \pm 0.20^{\mathrm{a}}$ & \multirow{2}{*}{10} & $0.80 \pm 0.41^{\mathrm{aA}}$ \\
\hline $20-$ & & $1.00 \pm 0.00^{b}$ & & $1.00 \pm 0.00^{\mathrm{BB}}$ \\
\hline
\end{tabular}

Ps: In the same team, different lowercase letters represent significant difference in the level of 0.05 , and different capital letters represent great significant difference in the level of 0.01 .

\section{Conclusions}

Microteaching training time usage distributed mainly between 5-56 minutes, where the trainings in segment of 15 minutes and 36minutes+ were the least, totally less than $5 \%$, the most training time was segment of 11-15 minutes, about $30 \%$. Large parts of teaching time were focused on the period of 6-25 minutes, about $86 \%$.

Class skill usage comprehensiveness presented increase trend with teaching time increasing, which came to the highest point in the period of 26-30 minutes, then gradually decreasing. Therefore, the length of teaching time had great effect on teaching skills usage comprehensiveness.

There were significant differences between the segment of 1-5 minutes in 5mins division and 6 segments after 10 minutes. There was significant difference between the segment of 1-10 minutes and that of 20-30 minutes, 36 minutes+ in 10mins division, and the segment of 11-20 minutes was transitional part, no relationship with the other time periods. In $15 \mathrm{mins}$ division, there was no significant difference among the 3 segments. In 20mins division, there was great significant difference between the 2 segments with the most rational zoning. So, based on the rational zoning and significant effect, the sequence was as followed: $20 \mathrm{mins}$ division $>10 \mathrm{mins}$ division $>5 \mathrm{mins}$ division $>15 \mathrm{mins}$ division.

Language and explanation was the basic skills, no relationship with teaching time. In $10 \mathrm{mins}$ division, among the ten teaching skills, it was demonstration, blackboard writing and ending skills that had upper and lower fluctuation with teaching time increasing, but no significance because of small amplitude. Meanwhile, the skills of introduction, questioning, changing, strengthening, class management presented increasing trend with the increasing time, only did class management skill show significant difference. In 20mins division, only in the aspect of demonstration skill was there negative relationship between skill usage and teaching time, while, the results 
showed that the other 7 skills usage including introduction, questioning, changing, strengthening, blackboard writing, ending and class management, had positive relationship with teaching time. There were significant difference between the time and the 4 skills usage, including questioning, changing, strengthening, class management, which displayed the great significant difference between strengthening skill usage, class management skill usage and the time.

Through analyzing the characters of the relationship between teaching time and skills, the data verified that it was necessary and effective to make rational class teaching time scheme for achieving higher teaching efficiency.

\section{Acknowledgments}

Comprehensive Reform Pilot of Landscape Major in GUANGDONG Province (code: 230075010202)

Gardening Major Excellent Teaching Team Construction of SHAOGUAN University in GUANGDONG Province. (code: 5137).

Internet course building of Teaching Research Project of SHAOGUAN University (code: 70302-00070) $2015^{\text {th }}$ Teaching Reform Research Project of SHAOGUAN University (code: 70312-000015)

\section{References}

[1] DeRun YUAN, "Practice Orientation of Qualification Determination Examination of Primary and Middle School Teachers in Modern American", [J] Foreign education of primary and secondary schools, 2011 (4) : 12-15.

[2] EnShan LIU, Teaching Theory of Middle School Biology, [M] HIGHER EDUCATION PRESS, 2003.

[3] LiQun SHENG \&WenLi WU, The Teaching Time Research Model and its Features, [J] Curriculum Materials· Methods, 2002(10) : 18-23.

[4] $\mathrm{Xu}$ WANG, Mathematical model of high school classroom teaching time allocation, $[\mathrm{J}]$ Education Tribune, 2012 (3) : 92-93.

[5] DaoSheng GUO \& ZhiWei YUAN, The Golden Rule and The Distribution of Classroom Teaching Time [J]. TEACHIING and MANAGEMENT 1997(5):40-41. 